João Rodrigo Araujo Santana ${ }^{1}$

Ubiraneila Capinan ${ }^{2}$

\title{
SOCIOLOGIA RURAL NO BRASIL, DILEMAS CLÁSSICOS E CONTEMPORÂNEOS: UMA ENTREVISTA COM OS PROFESSORES ANTÔNIO DA SILVA CÂMARA E LÍDIA CARDEL
}

\author{
RURAL SOCIOLOGY IN BRAZIL, CLASSIC AND CONTEMPORARY DILEMMAS:AN \\ INTERVIEW WITH PROFESSORS ANTÔNIO DA SILVA CÂMARA AND LÍDIA CARDEL
}

\begin{abstract}
Resumo
O presente texto é uma entrevista realizada com os professores Antônio da Silva Câmara e Lídia Cardel, docentes da Universidade Federal da Bahia e coordenadores do Núcleo de Estudos Ambientais e Rurais (Nuclear/CNPq). Com larga experiência na temática da Sociologia Rural, Antônio Câmara e Lídia Cardel orientaram diversos trabalhos na área das Ciências Sociais, seja na graduação ou na pós-graduação, sendo responsáveis pela formação de diversos pesquisadores que se dedicam a tal assunto. Nessa entrevista, os professores discorrem sobre as suas trajetórias acadêmica e profissional, bem como analisam algumas problemáticas clássicas que atravessam os estudos sobre o mundo rural no Brasil.
\end{abstract}

Palavras-chave: Sociologia rural. Campesinato. Reforma agrária. Migração. Representações sociais.

\section{Abstract}

This text is an interview with professors Antônio da Silva Câmara and Lídia Cardel of the Federal University of Bahia and coordinators of the Center for Environmental and Rural Studies (Nuclear/CNPq). With extensive experience in the subject of Rural Sociology, Antônio Câmara and Lídia Cardel supervised several studies in the field of Social Sciences, in both undergraduate or graduate courses, being responsible for the training of several researchers dedicated to Brazilian Rural Sociology. In this interview, the pro-

1 Doutorando em Ciências Sociais pela Universidade Federal da Bahia. Professor substituto da Universidade Estadual de Feira de Santana (UEFS/BA). E-mail: joaorodrigoas@hotmail.com

2 Bacharel em Sociologia e licenciada em Ciências Sociais pela UFBA, Antropóloga filiada a ABA, Mestre em Ciências Sociais pela UFBA, Doutoranda em Ciências Sociais pela UFBA e Professora do Instituto Federal Baiano - IFBaiano. E-mail: ubiraneila.capinan@gmail.com 
fessors talk about their academic and professional trajectories, and they analyze some classic issues that involve studies on the rural world in Brazil.

Keywords: Rural sociology. Peasantry. Agrarian reform. Migration. Social representations.

\section{INTRODUÇÃO}

Abrimos esse dossiê de Sociologia Rural com uma entrevista realizada com os professores Antônio da Silva Câmara e Lídia Cardel, docentes da Universidade Federal da Bahia e coordenadores do Núcleo de Estudos Ambientais e Rurais (Nuclear/CNPq). Com larga experiência na temática da Sociologia Rural, Antônio Câmara e Lídia Cardel orientaram diversos trabalhos na área das Ciências Sociais, seja na graduação ou na pós-graduação, sendo responsáveis pela formação de diversos pesquisadores que se dedicam a tal assunto. Ambos têm uma vasta produção acadêmica, com publicação de livros, participação em coletâneas e artigos publicados em periódicos especializados.

A professora Lídia Cardel realizou seu pós-doutorado em Sociologia pela Universidade de Estrasburgo/França (2012-2013), é doutora em Antropologia Social pela Universidade de São Paulo (2003) e é mestre na mesma área pela Universidade de Brasília (1992). Em sua trajetória, realizou inúmeras pesquisas e atividades de extensão junto a comunidades tradicionais e camponesas, transitando entre as áreas da Sociologia Rural e Ambiental, se debruçando sobre temas como: movimentos messiânicos; movimentos socioculturais rurais e urbanos; território e construções identitárias. Já o professor Antônio da Silva Câmara graduou-se em Ciências Sociais na UFBA em 1975, três anos depois concluiu o seu primeiro mestrado na Universidade de Brasília, com a dissertação intitulada "Hegemonia e crise social no Brasil (1950-1964): a ideologia dominante em face as ligas camponesas", e em 1984 obteve um novo mestrado na Uiversité Paris Diderot,com a tese "La question de la réforme agraire au Brésil". Nos dez anos seguintes, dedicou-se à sua tese de doutorado em Sociologia na Université de Paris VII, intitulada "La Question de la Réforme agraire au Brésil Idéologie et réalité (1950-1980)". E realizou seu pós-doutorado no Centre national de la recherche scientifique/Universidade Toulouse le Mirail (França), em 2000. Entre teses, dissertações e monografias, o professor Câmara orientou cerca de noventa produções acadêmicas. Atualmente realiza pesquisas na área da Sociologia da Arte, explorando temas como: representações sociais no cinema; cinema e ideologia.

É enorme a importância dos professores Antônio Câmara e Lídia Cardel para a formação em Ciências Sociais na Universidade Federal da Bahia e, por 
isso mesmo, o empenho em realizar a presente entrevista, na qual os professores discorrem sobre as suas trajetórias acadêmica e profissional, bem como analisam algumas problemáticas clássicas que atravessam os estudos sobre o mundo rural no Brasil. Essa entrevista foi pensada, num primeiro momento, para ser realizada de forma presencial, contando com a participação conjunta dos dois professores e dos entrevistadores. Contudo, em razão do distanciamento social requerido pela pandemia da Covid-19, as entrevistas foram realizadas remotamente - o professor Câmara enviou suas respostas por escrito $\mathrm{e}$ a professora Lídia encaminhou áudios com as respostas, que foram posteriormente transcritas - e são aqui apresentadas em separado. Algumas perguntas se repetem nas duas entrevistas, outras são específicas, voltadas para as temáticas atualmente pesquisadas por cada professor.

\section{COM A PALAVRA, A PROFESSORA LÍDIA CARDEL ${ }^{3}$}

[Lídia Cardel] Abro essa entrevista agradecendo ao convite que me foi feito por Ubiraneila Capinan, que faz parte do conselho editorial da revista Prelúdios desde o primeiro número. Uma revista que eu vi nascer no seio do Programa de Pós-Graduação em Ciências Sociais, e que tem um papel fundamental na divulgação e na transmissão do conhecimento científico gerado nos mais variados campos de estudos. A temática que vocês me trazem para dialogarmos, um dossiê sobre Sociologia Rural, me é muito caro, até porque eu faço parte e sou membro do Núcleo de Estudos Ambientais Rurais, que foi fundado por pesquisadores da Universidade Federal da Bahia (UFBA) em 1998, tendo como os primeiros coordenadores os professores Antônio Câmara, do departamento de Sociologia, e Sylvia Maia, do departamento de Antropologia, dois grandes expoentes dos estudos rurais da UFBA. Dito isso, acho importante frisar que optei por fazer essa entrevista de forma oral, exercendo a oralidade como um ponto de deslocamento para que as ideias fiquem livres e deem margem à fruição do pensamento. Quando somos convidados a fazer uma entrevista, nós estamos acostumados a interlocução olho a olho. Existe aí uma demanda não só da palavra dita, mas também uma demanda da troca de olhares, da entonação da voz, do ambiente que se cria para uma entrevista e, nesse momento de excepcionalidade que estamos vivendo, apartados da convivência por meio do afastamento social imposta pela pandemia do Covid-19, me ouvir gravando me dá a sensação de uma proximidade psíquica. Estamos circunscritos ao espaço das nossas casas e, ao mesmo tempo, nos sentimos presos por algo invisível e ainda inexplicável em sua plenitude. Estamos presos porque faz parte de um contrato social que estabelecemos com a sociedade de que devemos estar em casa para que 
o vírus não circule (apesar da necropolítica, enquanto política de Estado, imposta pelo grupo que chegou ao poder em 2018) e, por isso mesmo, nós só podemos circular virtualmente pela nossa imagem e pela nossa voz. Essa interlocução, onde a pergunta vem acompanhada de todo um conjunto não narrado, não dito, onde o corpo de quem estabelece a comunicação está ausente, é de certa forma um privilégio. E nesse momento eu vou fazer aqui quase um monólogo com o que me foi enviado e gosto muito desse exercício. É um aprendizado de imaginação, inclusive, no sentido de que eu estou idealizando que estou na frente de pessoas que eu conheço e que transitam dentro do Núcleo que atualmente eu coordeno, e que fazem parte da minha trajetória na Universidade Federal da Bahia.

[Revista Prelúdios] Segundo José de Souza Martins (2001, p. 32), “[...] o mundo rural tornou-se objeto de estudo e de interesse dos sociólogos rurais pelo 'lado negativo', por aquilo que parecia incongruente com as fantasias da modernidade. Não por aquilo que as populações rurais eram e sim pelo que os sociólogos gostariam que elas fossem". O quão de projeto de modernidade houve/há na Sociologia Rural brasileira?

[Lídia Cardel] São múltiplas questões colocadas ao mesmo tempo. Compreendo que Martins, quando aponta o "lado negativo" do approach sociológico sobre a ruralidade brasileira, esteja se referindo à abordagem crítica que as ciências sociais realizaram sobre o processo da modernização conservadora no campo por meio de uma densa produção intelectual entre as décadas de 1970 e 1980, com uma forte abordagem marxista, na qual ele mesmo fez excelentes contribuições com as suas obras. Cito aqui três dentre a vasta produção deste autor: A Imigração e a crise do Brasil agrário (1973), Capitalismo e tradicionalismo (1975) e Os camponeses e a política no Brasil (1981). O que temos que ter em mente é que as projeções feitas de forma autoral por alguns sociólogos, inclusive por Martins, não correspondem ao todo do que foi produzido pelo pensamento sociológico brasileiro sobre as nossas ruralidades. O Brasil passou por uma transformação histórico-social intensa entre 1930 até 1980, com uma densa reestruturação do tecido social e político do Estado Nacional e, consequentemente, das sociabilidades urbanas e rurais. Para termos uma ideia, no ano 2000 , apenas $22 \%$ da população vivia no campo e, atualmente, somente $16 \%$ da população brasileira vive em zonas consideradas rurais. E essas zonas rurais não estão insuladas, mesmo que sejam distantes de grandes centros urbanos, pois estão permeadas por um mundo altamente tecnificado. Portanto, quando nos debruçamos sobre os estudos rurais, nos voltamos para os estudos sobre os projetos de modernidade impostos e propostos para o Brasil como um todo. Inclusive, o projeto de modernidade construído por meio de uma ideologia desenvolvimentista, que veio lá do início do século XX, e foi elaborado como um processo único de civilidade na década de 1930 pelo Estado Novo, fincou raízes tanto na ala conservadora como na ala progressista brasileira; e aqui, sendo bem sim- 
plista quanto ao panorama politico brasileiro dos últimos 100 anos. Nesse processo, a questão rural foi tratada como um problema a ser resolvido à posteriori e nunca tivemos na nossa história um governo capaz de implementar politicas efetivas para a resolução da nossa infame concentração fundiária mantida à custa de extrema violência. Em suma, voltando à pergunta central, o campo de estudo da Sociologia Rural é tão diverso quanto a realidade ao qual se propõe analisar e pesquisar. Há uma incomensurabilidade entre a análise macroanalítica, que elabora (e elaborou) uma "imaginação sociológica" sobre o devir do mundo rural, e a enorme diversidade da realidade local, regional e nacional dos mundos rurais brasileiros; realidades múltiplas que o pensamento sociológico nunca dará conta de expor. Assim, vejo essa afirmação de Martins como uma provocação positiva para um diálogo acerca do que já produzimos sobre esta temática nas últimas décadas.

[Revista Prelúdios] Como a modernidade apregoada e a demanda por agentes públicos das populações rurais coabitam com a peonagem, o trabalho escravo e a escravidão por dívida na expansão da fronteira do agronegócio no norte do país, documentada por José de Souza Martins no seu livro Fronteira: a degradação do outro nos confins do humano (1997)? Que projeto modernizador é este que devora o outro/humano?

[Lídia Cardel] Esta contradição é algo amplo na realidade da sociabilidade brasileira. Num processo civilizatório de 520 anos, com tantas nuances e tantas regionalidades, que foi reorientado pelo Direito Pombalino (1750) $e$ pela Lei das Terras de 1850, e marcado pelo maior regime escravista das américas (1539 a 1888), não podemos falar de modernidade sem nos remeter à dualidade senhor/escravo, que foi (e ainda é), a base para a formação da nossa sociedade patrimonialista. Eu não gosto dessa redução dualista, mas aqui estou me referindo a uma sociedade que estabeleceu um regime estamental baseado em relações clientelistas e familísticas, onde a razão moderna penetra à conta gotas ou pelas frestas. Nesta fricção entre éticas e moralidades distintas, existe um ruido entre a racionalidade do tempo, enquanto uma mercadoria, e do tempo como um marcador de diferenças essencialistas. E nesse rescaldo convivemos tanto com as formas mais contemporâneas de relações trabalhistas, quanto com as formas mais abjetas de apropriação do tempo de vida de grupos sociais, especialmente dos camponeses (históricos e/ou étnicos), o grupo ou classe social mais inviabilizado dentre todos da nossa história oficial. Um grupo tão invisivel que só conseguiu protagonismo em rebeliões, conflitos, movimentos messiânicos e sociais e pela negação daquilo que the é essencial: o camponês brasileiro é um sem-terra. E dentro dessa pauta ampla da luta por terras observamos, pós constituição de 1988, uma emergência de múltiplas campesinidades por meio de uma ampla dinâmica etnogênica. Assim, não podemos analisar todas as contradições e antagonismos impetrados pela lógica da modernidade capitalista sem falar nas pautas identitárias como um contradiscurso às barbáries impostas pelo 
capital em regiões de fronteiras agrícolas, que avançam sobre as terras indígenas e quilombolas desde a década de 1960. E, nesse processo, resta ao camponês a errância, como nos mostra de forma brilhante Maria Aparecida Moraes e Silva, em sua tese de livre docência intitulada "Os Errantes do fim do século" (1999). Nesta obra, a autora nos mostra a gênese do sem-terra do vale do Jequitinhonha $(M G)$ na década de 1960, sua transformação em boia-fria nos canaviais paulistas nas décadas de 1970 e 1980, até o seu "desaparecimento" imposto pela modernização da cultura sucroalcooleira em fins do século XX. Em 40 anos, o campesinato negro da região nordeste de Minas Gerais teve suas terras arrestadas pelo projeto de reflorestamento de maciços de eucalipto, tornou-se uma massa de migrantes (que só possuía um único capital: a capacidade de lidar com a terra), foi absorvido no trabalho de corte de cana na região do oeste de São Paulo em condições de precariedades inumanas e, por fim, "desapareceu" estatisticamente quando o setor se modernizou através da mecanização da colheita da cana de açúcar, técnica ironicamente estabelecida por uma lei ambiental que impôs ao setor a diminuição da emissão do gás carbônico. O capital, ao terminar com as grandes queimas dos canaviais para a posterior colheita, terminou também com a existência de um grupo de trabalhadores rurais. Entre serem camponeses em Minas até se tornarem trabalhadores rurais superexplorados nos canaviais paulistas e, logo após, desaparecerem, passaram-se apenas quatro décadas. E assim, desapareceram comunidades camponesas, territórios quilombolas, estruturas familísticas, hábitos alimentares, conhecimentos centenários e tantas vidas em um curto espaço de tempo. Voltando a Joséde Souza Martins e à sua obra Fronteira: a degradação outro nos confins do humano (1997), encontramos com o autor uma realidade estruturalmente parecida com a narrada por Maria Aparecida Moraes e Silva, com as mesmas crueldades envoltas em contradições perturbadoras. Ele narra o encontro de dois grupos sociais totalmente invisibilizados e desassistidos pelo Estado: os camponeses ribeirinhos do norte brasileiro e as comunidades indígenas da região amazônica. Com uma capacidade narrativa invejável, Martins retrata o encontro de um campesinato sem-terra e, por isso mesmo, transumante, com populações indígenas aos quais esse campesinato não conseguia (não consegue) conceber como seres humanos. O indio essencializado, por ser subsumido como não-humano, é um ser a ser dominado ou extirpado. Expulsá-lo das suas terras ancestrais torna-se uma ação plausivel e justificável para os grupos camponeses sem-terra. Nessa cosmovisão pós-colonialista a armadilha do Mito de Cronos, da força primordial entre a vida e a morte, pulsa intensamente. Ao mesmo tempo que exterminam as populações indígenas de várias etnias, ao serem os primeiros a invadirem territórios étnicos, são também os primeiros a serem exterminados com a chegada do Capital, que também não os consideram humanos. Na medida em que a fronteira agrícola avança sobre as terras recém conquistadas, transforma-os em peões em situação de trabalho análogo à escravidão, um termo técnico que apenas reforça que a servidão não desapareceu no Brasil. Mas, veja, a ampliação do capital se faz em cenários caóticos de lutas, não só lutas de classe, mas lutas étnicas, lutas 
que envolvem uma percepção de sentido de Nação que está lá atrás, envolta nas nossas estruturas históricas das plantations, como afirma Garcia Jr. Ser um camponês sem-terra é estar privado de uma ação maior que é transformar o tempo de vida em tempo de trabalho para si, é estar apartado de um imaginário e uma percepção de mundo em que o sujeito se vê enquanto um ser totalizado, um ser que se enxerga e se congrega no seu trabalho/modo de vida. Então, o tensionamento imposto pelo projeto da modernização em paises pós-coloniais é do "monstro animado", como afirma Marx; o que devora o outro, o que devora a humanidade, como constatam Martins e Silva. É um projeto de desumanização do outro, de desconstrução do outro, de vampirização do outro, de fetichização do outro, tirando desse outro a capacidade de reconhecimento de si. Esse outro, no caso aqui analisado o camponês sem-terra, ao mesmo tempo que é vampirizado pelo processo do não trabalho, do não acesso à terra como fonte e expressão do seu trabalho, é aquele que também estabelece uma relação de alteridade perversa com o denominado genericamente como "indio", um ser não-humano. E assim esse camponês, que a qualquer momento da vida pode ser transformado em peão escravizado, desumaniza um outro. Que outro é esse? É aquele outro condensado, essencializado e que representa os povos originários que têm na terra, não apenas a expressão do trabalho agrícola ou da exploração dos bens da natureza, mas uma relação holística com o ambiente, elaborando cosmologias que transformam o espaço em territórios identitários. Uma fronteira agrícola é um espaço de adensamento do confronto real e simbólico. Um topos criado pela ampliação do capital que estabelece o caos, normatizando a violência em vários niveis, petrificando as relações e privilegiando a coisa ao humano. O projeto da modernidade para os países pós-colonizados é um projeto de desumanização. A modernização no campo é uma máquina de desumanização das alteridades, onde a apropriação dos bens da natureza como uma mercadoria desestrutura as relações para colocar de forma retilínea, linear, a reprodução do capital. Daí vemos as contradições: enquanto a criação de gado é monitorada com chips, drones e vacinas de última geração, os trabalhadores são mantidos em situação de escravidão e privação. Não há contradição nesta cena pela ótica do capital. Quando focamos no significado dessa noção de modernidade para pensar as transformações no campo e do campo, e sobretudo as relações entre a cidade e campo, nos deparamos com as transformações das relações sociais que estão acontecendo no mundo rural e que não seguem um itinerário único, mas muitos caminhos alternativos. Hoje, já na segunda década do século XXI, nós ainda estamos confrontando o conceito de modernidade com o envelhecido conceito de desenvolvimento. O que vemos atualmente no Litoral Norte baiano, por exemplo, e que faz com que repensemos que a fronteira agrícola não é apenas a fronteira do distante, dos confins do mundo, como é colocado por José de Souza Martins, é que a fronteira é o espaço do conflito por excelência: ela se reproduz na indústria do turismo ambiental ou na agricultura empresarial. Precisamos refletir que as relações do mundo rural são imaginadas como se ainda se estabelecessem numa falsa oposição entre campo e cidade. Maria Isaura Pereira de Queiroz, 
em 1969, já apontava que o Brasil vivia a falsa oposição entre um mundo rural atrasado, isolado, insulado e um mundo urbano moderno e transformador. Essa discussão, que já tem mais de cinquenta anos, ainda causa forte impactos no campo dos estudos rurais e ambientais. Por fim, no sentido da lógica imposta pelo capital, não há contradição entre a modernização no campo e a manutenção do trabalho análogo à escravidão que, a meu ver, é trabalho escravo propriamente dito. Não há uma contradição na medida em que a questão do tempo é inexorável: o capital "quer" se reproduzir o mais rapidamente possivivel. Dessa forma, a lógica imposta nos espaços denominados de "fronteira" é o da aniquilação e/ou enfraquecimento da presença do Estado na mediação com o trabalhador rural, com o camponês e com os grupos identitários, desumanizando as relações e normalizando condições de existências extremamente penosas. Nas "fronteiras" os valores de civilidade se perdem e a brutalidade se normatiza: dorme-se em qualquer canto, come-se em latas, usa-se trapos como roupas e, enfim, a vida humana se torna dados estatísticos.

[Revista Prelúdios] Em sua tese de doutorado, "Migração, liminaridade e memória: um estudo sobre o choque entre imaginários e (re)construção de identidades", a senhora estuda as migrações. Como elas estão ligadas com o processo modernizador do campo?

[Lídia Cardel] A minha tese de doutorado se pautou por questões objetivase subjetivas do processo migratório enquanto um processo de desenraizamento. Meu objetivo era compreender como indivíduos que saiam de grupos sociais visto como tradicionais vivenciavam as experiências de deslocamento de um espaço identitário para outro, desconhecido e distante. Naquele momento, a crescente "desruralização" da população mundial ainda era uma temática que impulsionava os estudos e as pesquisas sobre como as dimensões campo e cidade se estruturavam. Eu então parti da minha dissertação de mestrado, uma etnografia realizada durante cinco anos numa comunidade camponesa localizada no município de Barra do São Francisco, noroeste do Estado da Bahia. Esta comunidade tem um histórico de migração para o sudeste brasileiro desde a década de 1930, período de intensa industrialização da cidade de São Paulo. Esse movimento marcou enormemente a dinâmica e a sociabilidade daqueles camponeses por décadas, construindo uma memória de deslocamento. Em contrapartida, o que me interessava no primeiro momento do meu trabalho etnográfico com a comunidade dos Brejos de Olhos d'água, era compreender o modus vivendi daquele grupo camponês, a sua relação com a terra-patrimônio, com as ancestralidades, com o território, ou seja, me interessava realizar uma "descrição densa" no sentido clássico. Porém, a migração histórica do grupo produzia movimentos internos tão profundos que tornou-se tema de pesquisa do meu doutoramento. Não era possivel compreender aquela sociabilidade sem olhar para os caminhos que eles criaram de idas e vindas. Assim, eu me vi levada a realizar uma 
outra etnografia, só que da comunidade que os migrantes haviam criado na cidade de São Paulo, na zona leste, numa vila operária que havia surgido ao redor de uma fábrica de vidros. A fábrica não mais existia desde a década de 1970, mas havia sido a porta de entrada para inúmeros migrantes do noroeste baiano em São Paulo. A literatura antropológica e sociológica sobre o campesinato brasileiro aponta que a migração é tanto uma estratégia de esvaziamento do patrimônio camponês (muitos filhos e pouca terra), como uma porta de fuga da falta absoluta de acesso à terra e suas consequentes situações de precariedades e violências. As mudanças bruscas provocadas pela modernização alteraram o panorama das sociedades ditas tradicionais, ou, como eu prefiro designar, comunidades centenárias, provocando um intenso turbilhão sociocultural, tendo como expressão máxima uma aceleração abrupta do processo migratório da população do campo para a cidade. Em poucas décadas nos urbanizamos, mas as lutas fundiárias não cessaram, ao contrário, se agudizaram, transformando as estruturas fundiária urbanas tão complexas como as estruturas fundiárias rurais.

[Revista Prelúdios] Como o rural pode subsistir como ethos fora do espaço, da temporalidade e das economias que giram em torno do mundo agrícola, do campesinato? Como ele se apresenta nesta condição?

[Lídia Cardel] Na minha perspectiva, o ethos camponês subsiste nas franjas das grandes capitais brasileiras, pois os migrantes trazem consigo vários aspectos das sociabilidades rurais: o plantio de quintais, a criação de pequenos animais, os hábitos alimentares etc. A cidade de Salvador tem na sua malha territorial esta fluidez. Em vários bairros observamos hortas, plantios e criação de animais de pequeno, médio e grande porte como galinhas, porcos, cavalos, bois. Os nomes dos bairros fazem referência às antigas fazendas e, quando trafegamos com calma e com um olhar mais apurado para as delicadezas cotidianas, vemos uma tropa de cavalos sendo asseados na praia de Amaralina às 6 horas da manhã, uma porca prenha solta pelo bairro da Boca do Rio em pleno sol do meio-dia, ou mesmo, crianças nos pés de abacateiros ejacas na Baixa de Quintas. A hiperurbanização não foi capaz de apagar as sociabilidades gestadas. E, na verdade, localizar as atividades dos seres humanos com a terra e com os animais como sendo algo que deve existir apenas no meio rural é um desacerto. Uma inadvertência, inclusive, que repetimos quando dividimos os campos dos estudos sociológicos em urbanos e rurais. Não é possível, na atualidade, georreferenciar as ações entre os seres humanos e o meio ambiente por meio do que é rurale do que é urbano. Por exemplo, uma das pautas mais prementes hoje é a questão fundiária brasileira, que possui uma concentração tanto no meio rural quanto no urbano. O chão de morada e o chão de trabalho do camponês, do trabalhador rural e do trabalhador das indústrias de bens e serviços está concentrado nas mãos de poucas empresas e grupos de pessoas. Inclusive, essas empresas e grupos adquiriram e se apropriaram desse tecido fundiário em algum 
momento da cadeia dominial da propriedade (seja ela rural ou urbana), de uma forma pouco clara dentro dos princípios jurídicos. James Holston esclarece esta questão histórica da estrutura fundiária brasileira no seu famoso artigo intitulado "Legalizando o ilegal: propriedade e usurpação no Brasil" (2013). Portanto, apesar das especificidades que ainda permanecem, ao meu ver, a divisão de rural e urbano na atualidade é muito mais sobre a divisão de territórios administrativos do que de territórios que demarcam processos de sociabilidades distintas, ou seja, é uma divisão imposta pelo georreferenciamento estatal que dirige as políticas públicas macro e micro econômicas. Podemos falar, por exemplo, da região do Litoral Norte da Bahia, onde os pesquisadores do Nuclear desenvolvem pesquisas desde 2009. Essa região fisica comporta uma sobreposição de muitos territórios, sendo o maior deles a Área de Proteção Ambiental do Litoral Norte. Dentro daquela APA existem vários municípios, inúmeras comunidades tradicionais e uma vasta faixa litorânea onde a indústria do turismo implantou ithas urbanizadas como os resorts, hotéis, condomínios de moradia, entre outros. Na faixa que vai do município de Lauro de Freitas até a divisa do estado de Sergipe, o urbano e o rural se entrelaçam com todas as ambiguidades possivivis e imagináveis. Em suma, esse devir camponês não se coloca de forma oposta ao devir citadino. Eles estão imbricados no processo de formação dos tecidos sociais aos quais vão se construindo e se gestando. Delimitar o que é urbano e o que é rural, em determinadas instâncias, é um processo de delimitação epistemológica que não abarca a pulsão das vivências humanas. Nós ainda demarcamos em campos de estudos sociológicos distintos, mas no mundo das existências contemporâneas esses dois âmbitos, o rural e urbano, estão completamente entrelaçados e as suas atividades condensadas. Vemos essa fusão nos discursos da agroecologia, do veganismo, da bioconstrução, em suma, dos ativismos que envolvem a integração homem/natureza por meio de um discurso "holistico politizado". Nessa visão de mundo que denomino de "holismo politizado", a agricultura, que sempre foi vista como uma atividade eminentemente rural, está sendo requisitada para ser também uma atividade do mundo urbano. As pessoas com "consciência alimentar" estão sendo levadas, inclusive pela questão do ativismo alimentar, a terem em seus pequenos apartamentos hortas suspensas, hortas verticais, composteiras com minhocários, entre outras ações que há algumas décadas seriam ações denominadas e localizadas em pequenas propriedades rurais com grandes quintais produtivos. E aqui nos deparamos com um assunto clivado pela questão de classes sociais. Não podemos deixar de pontuar que os subúrbios e as periferias dos grandes centros urbanos brasileiros nunca deixaram de possuir suas hortas e áreas de criação de animais, como já afirmei anteriormente. Enquanto uma visão de mundo e uma ideologia, o ethos do "holismo politizado" ultrapassa a relação do homem com a terra e com os recursos naturais, estabelecendo uma busca de simetria entre o homem e a natureza. Ou seja, o ethos camponês é revivido por esse "holismo politizado" como um processo biopolitico. 
[Revista Prelúdios] "Entre 1985 e 2018, 1938 pessoas foram executadas em conflitos por terra, água e trabalho no Brasil e 1789 desses casos (92\%) continuam sem qualquer responsável julgado ou preso. [...] Do total de mortes, apenas 370 tiveram suspeitos identificados, mas apenas 117 julgamentos foram realizados. As condenações foram realizadas apenas para pouco mais da metade dos mandantes apontados pela polícia e um terço dos executores identificados". Os dados são da Comissão Pastoral da Terra - CPT (DIAZ, 2019, 12 jun). Na mesma reportagem, a procuradora dos direitos humanos do Ministério Público, Débora Duprat, alerta que "As propostas de Bolsonaro que visam armar os proprietários rurais vão deixar os lugares onde a violência já impera ainda mais violentos". $\mathrm{O}$ conflito do campo resultando em morte é problema social que parece crônico no Brasil. Qual balanço a senhora faz desta problemática da questão agrária e qual o horizonte dela no atual governo do presidente eleito em 2018?

[Lídia Cardel] O Brasil é um país violento. Nenhum país pós-colonial deixou de ser violento, seja no meio rural ou no meio urbano. Por séculos, o projeto dos vários governos que se sucederam, ou foram coniventes ou foram os fiadores da violência real e estrutural do Estado Brasileiro. O que vivemos atualmente é a institucionalização da dizimação das populações plurais por todo o território nacional. Esse projeto faz parte do nosso processo civilizatório e, atualmente, mostra a sua face mais trágica, pois as estruturas democráticas estão sob ameaça. Infelizmente, os movimentos sociais ficaram fragilizados pelo processo de burocratização a que se submeteram a partir de 2003. É complexo aqui analisar este processo, mas o que percebemos hoje é uma incapacidade desses movimentos sociais de reagirem à avalanche de ações arbitrárias e genocidas do atual governo. Estamos todos paralisados e atônitos. Sobre esta realidade de violências reais e simbólicas, Alain Touraine, em suas últimas obras, afirma que a saída para a sociedade contemporânea está na ascensão dos movimentos sociais com pautas feministas e ecológicas. Por outro lado, essa visão eurocêntrica sobre como a sociedade civil poderá se organizar para superar os desastres sociais e ambientais que marcam o século XXI não se coaduna com as realidades heterogêneas do mundo não-europeu. Os intelectuais latino-americanos, africanos e asiáticos que se centraram no que foi designado como "Estudos sobre a Subalternidade" falam em unissono com a mulher indiana e intelectual Spivak: pode o subalterno falar? Eu diria que a partir dessa indagação seminal temos outra indagação mais visceral: pode o subalterno viver? Que vida é possivel ao subalterno? E assim chegamos em uma outra grande intelectual latino-americana, Rita Segato (2003), que em sua obra "As estruturas elementares da violência" (obra que faz uma alusão crítica à obra clássica de Lèvi-Strauss, "A estruturas elementares do parentesco") reafirma, como Touraine, que a atual sociedade pautada na lógica hegemônica do patriarcado capitalista é seminalmente destrutiva, violenta e humanamente pobre. É o que vivemos 
hoje no Brasil. Segato nos faz refletir sobre as entranhas da violência do capitalismo patriarcal. Não podemos deixar de demarcar que apesar das Ciências Sociais, de forma clássica, incensar positivamente o ethos das tradições, inclusive o ethos camponês, estes ethos são patriarcais e violentos em suas raizes, apesar de serem subalternos. As várias camadas de subalternidade acabam invisibilizando questões centrais para uma sociedade humana que busca utopicamente se unificar, se transformar e criar uma simetria entre os seres humanos e não-humanos, para buscar aqui a denominação tão cara a Bruno Latour. Em suma, a violência no Brasil se mostra acachapante pelos números de mortes que envolvem a questão agrária, o racismo estrutural, - feminicídio (e suas várias faces vinculadas à população LGBTQI+) e as violências históricas imersas em estruturas hierárquicas de subalternidades que normatiza a morte daqueles que "podem" ser eliminados.

[Revista Prelúdios] Como pensar a trajetória da Sociologia Rural no Brasil considerando a sua relação com o projeto extensionista rural de levar tecnologia ao campo (Revolução Verde) - e a formação de cientistas sociais habilitados ao trabalho de garantia de direitos, historicamente negados, aos grupos subalternizados?

[Lídia Cardel] Aqui são várias questões colocadas de uma só vez. O papel da Sociologia Rural, como um campo de estudo e de pesquisa, é propor uma visão crítica por meio de estudos teoricamente e epistemologicamente orientados. A questão da extensão rural não necessariamente está ligada à esta área da sociologia. Por conseguinte, a formação de cientistas sociais que são chamados a trabalhar como técnicos em órgãos estatais, e que têm como função aplicar políticas públicas transversais e redistributivas, depende enormemente de um projeto maior de governo. São questões muito distintas para serem conectadas de forma tão direta. No período do governo do Partido dos Trabalhadores, entre 2003 à 2015, até o golpe jurídico no mandato legítimo da então presidente Dilma Rousseff, havia um conjunto de políticas que se entrelaçavam como, por exemplo, O Brasil Quilombola, o Programa Nacional de Fortalecimento da Agricultura Familiar - PRONAF (nas suas várias versões), entre outras, que mesmo de uma forma tímida, implementaram algumas ações voltadas ao campesinato e à agricultura familiar. Nesse contexto, não apenas os sociólogos com especialização em estudos rurais foram chamados para compor o corpo técnico de vários ministérios e secretarias, como também economistas, geógrafos e muitos profissionais das ciências sociais aplicadas. Esta realidade foi interrompida bruscamente com o impeachment. O que não quer dizer que o papel da Sociologia Rural como campo de conhecimento e de formação de profissionais para a área técnica tenha sofrido uma transformação brusca, em sua essência, com a reviravolta política e a ascensão da extrema direita após a eleição de 2018. Não podemos esquecer que os cientistas sociais possuem uma parceria de longa data com as Organizações Não Governamentais (ONGs) que, na ausência de um Es- 
tado de bem-estar social, aparecem nos cenários regionais e nacionais para implementarem projetos sociais que são impregnados por uma visão desenvolvimentista e tecnificada, visão esta que se apresenta sempre por meio da ideologia da sustentabilidade. E aqui nós teríamos uma discussão ampla sobre os vários sentidos e conceitos de sustentabilidade que é usada, inclusive, como um discurso legítimo do capital, mas nós não vamos entrar nessa digressão. Neste sentido, a Sociologia Rural no Brasil possui uma via de mão dupla. Na academia, se volta para a produção de pesquisas essenciais para a compreensão crítica da realidade social brasileira e, na sua face sociotécnica, se debruça na aplicação de um conhecimento dirigido por projetos de desenvolvimento locais, regionais e nacionais. São politicas governamentais que não podem ser confundidas com a questão da Sociologia ou da Sociologia Rural como um campo de conhecimento.

[Revista Prelúdios] Surgida na década de 1970, a Sociologia Ambiental é compreendida como um campo gestado dentro da Sociologia Rural. Em que medida esta vem ganhando espaço acadêmico e relevância na sociedade em detrimento da primeira?

[Lídia Cardel] John Hannigan, no seu clássico livro intitulado "Sociologia Ambiental", publicado em 2009, faz um histórico bem fundamentado de como a sociologia ambiental se descolou epistemologicamente da Sociologia Rural e construiu um campo próprio dentro da Sociologia. O pensamento ambiental criou um discurso científico por meio dos conflitos dos usos dos recursos naturais, fruto do processo extremamente hostil da modernização no campo que impôs o uso de tecnologias intensivas de exploração do meio ambiente. Deste modo, mesmo tendo surgido no seio do grande campo da Sociologia Rural, o foco da Sociologia Ambiental voltou-se para os impactos ecológicos, criando, assim, a necessidade da demarcação de um novo campo de conhecimento que se voltasse para a concepção da sociedade de risco, dos princípios dos manejos híbridos, das questões da globalização e do fluxo ambiental, assim como dos comportamentos coletivos em emergências ambientais e desastres. E, assim, dentro da Sociologia Ambiental surgiu, mais recentemente, a Sociologia do Risco e a Sociologia dos Desastres. Estes campos e subcampos científicos fazem parte da história da ciência, como aponta Thomas Kuhn na sua obra clássica As estruturas de revoluções cientificas (1962). As transformações da realidade social produzem novas formas de análise, novos paradigmas e novas áreas de conhecimento.

[Revista Prelúdios] Fale-nos, brevemente, da sua trajetória de 33 anos como pesquisadora, que se inicia na Sociologia Rural com a monografia "Forte e fraco, dentro e fora: categorias culturais e estrutura de comunidade" e chega ao tema de sua pesquisa mais recente sobre trabalho sexual e cidadania, "Novos movi- 
mentos sociais, sexualidade e cidadania: um estudo de caso sobre o trabalho sexual como um campo de disputa política".

[Lídia Cardel] Vou começar falando da minha realidade de agora, onde me divido entre duas pesquisas aparentemente muito distintas: faço parte de um projeto do Instituto Nacionais de Ciências Tecnologia (INCT), coordenado pelo professor Charbel El-Hani, da área de Ensino em Ciências (do Instituto de Biologia da UFBA), intitulado "Estudos Interdisciplinares e Transdisciplinares em Ecologia e Evolução" (INCT IN-TREE), projeto guarda-chuva que reúne 13 projetos voltados para a questão ambiental, e no qual coordeno o projeto de pesquisa denominado "A sociobiodiversidade do Litoral Norte baiano: pesquisa interdisciplinar sobre os saberes e as práticas naturais, a mobilidade, as dinâmicas territoriais e o desenvolvimento rural sustentável em um bioma de Mata Atlântica", que congrega pesquisadores da área de Botânica, Genética, Etnologia, Educação e Sociologia Rural e Ambiental. Por outro lado, nas minhas pesquisas individuais que venho desenvolvendo nestes 30 anos de docência, possuo a prática de orientar estudantes de iniciação científica por meio de projetos que me levam a me vincular em outras áreas de conhecimento. Nesse momento, estou finalizando um projeto Programa Institucional de Bolsas de Iniciação Científica - PIBIC que busca mapear as lideranças dos movimentos sociais das trabalhadoras sexuais no Brasil. A minha prática de vida acadêmica sempre privilegiou a interdisciplinaridade e a capacidade de criar diálogos com várias áreas de conhecimento. O que não quer dizer que eu não tenha uma área de especialização, que está fincada nos estudos rurais e ambientais desde o início da minha vida acadêmica, quando fiz minha monografia de graduação na Universidade de Brasília, na área de estudos de campesinato, orientada pela professora Mireya Suárez, uma das fundadoras do departamento de antropologia da UnB. Com ela, aprendi que as ciências sociais caminham pelo terreno do diálogo e da compreensão de distintos campos de pesquisa e que faz parte da vida acadêmica ter coragem de se aventurar, de forma quase segura, por áreas aparentemente estranhas à nossa formação, sem deixarmos de nos aprofundar em uma área de conhecimento. Meu diálogo com as ciências biológicas, mais especificamente com a botânica, veio por uma necessidade de compreender holisticamente a relação do humano com o meio ambiente que o cerca. Por isso, desde 2006, muitos dos meus projetos de pesquisa são realizados com os meus colegas do Instituto de Biologia da UFBA, bem como com os parceiros de pesquisa da Universidade de Strasbourg, onde fiz meu pós-doutorado em 2012. Os parceiros da universidade francesa, com os quais mantenho uma troca acadêmica muito rica desde 2009, me trouxeram o diálogo com a Etnobotânica e com os estudos da Agricultura Urbana. Entretanto, a minha formação mais sólida se deu no mestrado, realizado entre os anos de 1988 a 1993, também na Universidade de Brasília, com a orientação primorosa de Klaas Woortmann. Com ele, aprendi que o trabalho etnográfico possui uma autoria, uma intensidade impar capaz de nos transformar como seres humanos. E, para além disso, com a orientação de Klaas, fui capaz de transfor- 
mar uma vivência etnográfica em um exercício acadêmico, algo que exige um esforço racional e emocional intenso. Já no meu doutorado, que realizei entre os anos de 1998 a 2002, sob a orientação de Renato Queiroz, na USP, foi um momento de consolidação de uma vida acadêmica que já tinha se iniciado em 1990, quando comecei a minha vida como docente. Naquele momento eu já era professora da UFBA, meus filhos, que são trigêmeos, eram pequenos, tinham apenas 3 anos, e as agências de fomento de pesquisa, como a Capese - CNPq, já haviam burocratizado a pós-graduação com tempos bem delimitados, o que dificultava sobremaneira a vida dos antropólogos que optavam por realizar trabalhos de campo extensos. Mesmo assim, fiz dois campos etnográficos com duração de um ano cada, um no interior da Bahia, no mesmo campo que realizei minha etnografia para o mestrado, e o outro na zona leste de São Paulo, numa comunidade de migrantes baianos. E, por um milagre, defendi minha tese dentro do prazo. A minha pulsão de vida naquele período era tão intensa (e ainda é, mas dirigida para outras instâncias da vida), que a vivência de uma maternidade impar com a vida de trabalho não entrou em rota de colisão. Aliás, ao contrário! Eu diria que ter tido uma maternidade distinta me fez conseguir superar as dificuldades de um trabalho acadêmico que se apresentou como um processo de extrema disciplina, com um tempo muito curto para ser realizado e finalizado à contento. A fusão da minha maternidade com a minha energia criativa me deixou muito feliz naquele período, mas essa junção não é a regra para as mulheres na Academia. Eu tive sorte! Mas vocês me perguntaram sobre a minha aparente multifocalidade de temas de pesquisa. Pois bem, eu respondo com uma questão: como não se apaixonar por toda a diversidade do humano? Claro que a Academia impõe um produtivismo que orienta o pesquisador a se hiperespecializar em apenas uma área de conhecimento. Esta é a contradição mais dura do fazer científico e das politicas que regem o meio acadêmico. Não acredito que um cientista social deva deixar de estudar vários temas, mesmo que se veja impelido a ser especialista em um único campo. A questão não é apenas a especialização, mas ainda existe a cobrança de que o campo escolhido deva ser socialmente relevante. E esta relevância normalmente é imposta pela economia e pela política que envolvem o fazer científico e que deixa de lado a economia dos afetos. Os meus 33 anos de vida acadêmica, e trinta de docência, têm sido um processo de aprendizado e de negociação entre o desejo pelo todo e a vivência da realidade objetiva da ciência como uma ação orientada.

\section{COM A PALAVRA, O PROFESSOR ANTÔNIO CÂMARA ${ }^{4}$}

[Revista Prelúdios] Fale-nos, brevemente, da sua trajetória de cerca de 45 como pesquisador, que tem seu primeiro marco de pesquisa na dissertação intitulada "Hegemonia e crise social no Brasil (1950-1964): a ideologia dominan-

4 <camara@ufba.br> 
te em face as ligas camponesas", e chega ao tema de sua pesquisa mais recente sobre "A Construção de um imaginário de nação no cinema norte-americano".

[Antônio Câmara] É um tempo muito longo para ser breve, mas vou falar sobre dois momentos importantes. O primeiro situa-se entre o mestrado em sociologia (1978) e o doutorado (1994), quando aproximei-me da Sociologia Rural, sobretudo pelo viés das lutas sociais, na época, queria resgatar as Ligas Camponesas e sua luta pela reforma agrária e percebi, ao longo da pesquisa, que isso não seria possivel sem abordar também toda a disputa no Congresso Nacional pela aprovação de uma lei de reforma agrária. Por isso, investiguei o movimento social, o seu discurso e o discurso ideológico que se contrapunha à reforma agrária. Curiosamente, observei que não consegui responder porque, após o golpe de Estado em 1964, uma lei de reforma agrária foi promulgada e jamais posta em prática. Por isso, pareceu-me incompleta minha pesquisa e levei essa tarefa para o doutorado, quando a ampliei, tentei compreender todos os discursos reformistas e antirreformistas no Congresso, no movimento social e na própria literatura científica, pelo menos até o início da década de 1980. Lembro-me que terminei a tese saudando o surgimento de um novo movimento social que não foi tratado na tese -o MST (Movimento dos Trabalhadores Rurais Sem Terra). De quando fiz a dissertação até a conclusão da tese fui prisioneiro da obsessão de entender por que a reforma agrária nunca foi efetivada no Brasil. Desde o surgimento do MST, mesmo antes de terminar a tese, comecei a tentar entender se este movimento enfim conseguiria a proeza da efetivação da reforma agrária, acompanhei suas lutas, particularmente a partir do massacre de Corumbiara, aproximei-me do movimento na Bahia, participando de eventos na condição de palestrante e observador do movimento. Do ponto de vista da pesquisa, elaborei um projeto sobre o MST na imprensa e dirigi uma série de dissertações e teses sobre a temática. Lecionei também diversas disciplinas sobre movimentos sociais rurais e tentei entender o surgimento do Exército Zapatista de Libertação Nacional - EZLN no México (mais tarde tema do pós-doutorado). Após a defesa da tese, senti-me livre para seguir caminhos já experimentados na sociologia da arte, mas até então secundarizado, e isso foi feito com momentos de transição, primeiro oferecendo disciplinas no âmbito da sociologia da arte no Departamento de Sociologia e na pós-graduação em artes na Escola de Belas Artes (1996), posteriormente expandindo para pesquisas sobre representação do rural no cinemae, por fim, abarcando as diversas dimensões da sociologia da arte.

[Revista Prelúdios] Como um sociólogo de formação marxista pensa a existência de camponeses no Brasil?

[Antônio Câmara] Não saberia responder de modo genérico, mas posso pensar a partir da minha própria experiência. Creio que é possivel analisar essa existência tendo como suporte Marx e Engels, em obras como as Lutas Camponesas na Alemanha, as Lutas de Classe na França, 018 Bru- 
mário de Luiz Bonaparte, Formações econômicas pré-capitalistas, dentre outras obras; também atentando para algumas obras fundamentais dos revolucionários russos como Lênin e Trotsky que analisaram o papel dos camponeses na aliança operário-camponesa na revolução russa, por fim levando em conta obras clássicas sobre os camponeses produzidas por Hobsbawm, Barrington Moore Júnior etc. No âmbito nacional, tanto os clássicos que estabeleceram duras oposições, como Caio Prado Júnior e Rui Facó, ou autores mais contemporâneos como Martins, nos permitem pensar a existência dos camponeses. No entanto, construir a compreensão de um campesinato no Brasil passa também por aproximações e distanciamentos dos próprios autores citados, pela apreensão da antropologia camponesa que descreve e caracteriza atividades rurais em diversas regiões do planeta. Voltando ao marxismo clássico, vemos que Marxe Engels reconheceram a existência dos camponeses como produtores autônomos e semiautônomos, no entanto não viram nesta classe (em que pese a análise das lutas camponesas na Alemanha) todas as condições para sua constituição enquanto classe para si, pois, o fato desse grupo social se encontrar vinculado à posse privada da terra, seria um efetivo obstáculo para uma oposição consequente à burguesia. Já os revolucionários russos perceberam em um país com predominância de atividades rurais que o campesinato seria um aliado fundamental para a revolução socialista, cunharam a partir disso a aliança operário-camponesa, mas com hegemonia do proletariado na condução do processo revolucionário. Por fim, alguns autores posteriores perceberam essa capacidade de luta dos camponeses e como sua resistência às classes dominantes perpassa a história do capitalismo. Pensando no Brasil, alguns autores marxistas transpuseram de forma automática a história da Europa e recriaram o feudalismo e as etapas para a revolução socialista, passando pela modernização dos camponeses que se tornariam assalariados; ou, como foi o caso de Prado Júnior, negaram sua existência, vendo em todas as relações sociais de produção no campo situações de assalariamento ou semiassalariamento. Superar essa dicotomia foi obra de investigações empíricas, realizadas ao longo da década de 1980, que permitiram a construção de um conceito de camponês capaz de dar conta das diversidades no país. Assim, vários estudos nos permitiram compreender como no campo é possível encontrar situações de assalariamento pleno convivendo com relações de produção camponesas e, por vezes, como o mesmo indivíduo é, ao mesmo tempo, camponês e assalariado, isso sem levar em conta o fenômeno dos sem-terra, expulsos da terra, muitas vezes habitantes das periferias das cidades, mas preservando forte ligação com a terra. Voltando agora para minha experiência, creio que os estudos clássicos, as pesquisas no Brasil e, sobretudo, as lutas sociais que estudei e acompanhei, permitiram-me compreender que temos sim no Brasil um campesinato, com proximidades e distanciamentos daquele estudado na Europa, que não se constitui em obstáculo à revolução social. Creio que em determinado momento o MST compreendeu isso e se tornou um protagonista das lutas mais avançadas no país. Enfim, o aspecto levantado por Marx e Engels relativo à consciência de classes, pode ser aplicado a esta classe devido à limitação da 
sua experiência com a propriedade privada, mas em países como o nosso, no qual a tendência à expropriação desta classe é imensa, a perspectiva de trabalhar a luta pela reforma agrária aliada a um comportamento coletivo, tal como percebeu o MST, aproxima o campesinato do proletariado em sentido lato (os assalariados e não apenas os operários). Assim, podemos pensar o campesinato a partir da tradição marxista, mas com os olhos abertos para os novos elementos postos pela realidade.

[Revista Prelúdios] Segundo José de Souza Martins (2001, p. 32), “[...] o mundo rural tornou-se objeto de estudo e de interesse dos sociólogos rurais pelo 'lado negativo', por aquilo que parecia incongruente com as fantasias da modernidade. Não por aquilo que as populações rurais eram e sim pelo que os sociólogos gostariam que elas fossem." O quão de projeto de modernidade houve/há na Sociologia Rural brasileira?

[Antônio Câmara] Essa formulação de Martins é muito genérica e talvez possa ser aplicada a alguns clássicos da Sociologia Rural como Maria Isaura de Queiroz e seus estudos sobre comunidade rural; no entanto, creio que a Sociologia Rural avançou muito para compreender o protagonismo das populações rurais, apresentando um quadro de luta social que distanciava bastante os "camponeses" brasileiros da visão clássica sobre esta classe na Europa. Esses estudos ressaltaram a luta pela reforma agrária, a exigência de uma medida de mudança radical nas relações sociais no campo, em diversos periodos históricos. Assim, as lutas sociais orientadas por visões messiânicas, não alinhadas com os discursos politicos racionalistas, mas reivindicando outra forma de apropriação e produção no campo foram pesquisados (a exemplo de Canudos, na Bahia; e Contestados, no Paraná); estes estudos foram ampliados para entender a perspectiva politizada e socialista da luta das Ligas Camponesas e os discursos à esquerda e à direita sobre a questão da terra e, mais recentemente, a emergência de movimentos sem-terra, como o MST. Por outro lado, outra vertente da Sociologia Rural avançou na apreensão do desenvolvimento tecnológico, ou, dito de outra forma, na "expansão do capitalismo no campo", e, consequentemente, da consolidação da própria burguesia nacional. Provavelmente, a modernização do campo no Brasil, a via "prussiana" consistindo na exploração da terra e do trabalho em grandes propriedades rurais - latifúndios ou empresas rurais, tem sido vitoriosa contra todas as proposiçôes de democratização do uso da terra e de uma atividade econômica com perspectiva coletiva. Esses problemas foram e continuam sendo amplamente estudados pela Sociologia Rural, aos quais se acrescenta a polêmica entre a permanência ou não de um espaço rural em contraposição ao urbano ou a possiblidade destes dois espaços hoje constituírem um contínuo cada vez mais dificil de serem compreendidos de forma seccionada. Logo, a Sociologia Ruralé, de fato, contemporânea e busca a intersecção com outras sociologias, a antropologia, a geografia e a economia rural para avançar no estudo do seu objeto em permanente transformação. 
[Revista Prelúdios] Como pensar a trajetória da Sociologia Rural no Brasil - considerando a sua relação com o projeto extensionista rural de levar tecnologia ao campo (revolução verde) - e a formação de cientistas sociais habilitados ao trabalho de garantia de direitos, historicamente negados, aos grupos subalternizados?

[Antônio Câmara] Essa questão está bastante relacionada com a anterior, pois aponta para essa bifurcação entre a Sociologia Rural enquanto área de pesquisa, que ocorre predominantemente nas Universidades Públicas, permitindo a compreensão ampla dos dilemas do mundo rural e sua atividade prática relacionada com o Estado na implementação de políticas de modernização agrária, adotadas amplamente desde a promulgação do Estatuto da Terra. O Estatuto da Terra previa a reforma agrária, porém a sua parte modernizadora voltada para a tecnologia e extensão rural tornaram-se politicas estatais durante a ditadura militar. Naquele período, a atividade das secretarias de agricultura e de órgãos públicos nacionais como o Instituto Nacional de Colonização e Reforma Agrária - Incra e a Empresa Brasileira de Pesquisa Agropecuária - Embrapa, pautavam-se, de um lado, no impulso à modernização do campo com intenso apoio às grandes propriedades rurais; de outro, na aplicação de políticas compensatórias para os pequenos produtores rurais e, os que, no futuro seriam denominados "sem-terra". O trabalho dos sociólogos rurais consistiu, naquele período, em diagnosticar a situação no campo, colaborar com o extensionista rural e fazer pesquisas sobre os pequenos produtores rurais visando a implementação de programas de politicas compensatórias conduzidos por entidades internacionais (a exemplo do Banco Mundial). Essa situação sofre alguma alteração com a redemocratização e a perspectiva (não cumprida) de realização da reforma agrária, tanto por parte do Incra com medidas nacionais, quanto por parte de secretarias da agricultura nos estados. A multiplicidade de estudos diagnósticos para implementar a reforma agrária, bem como as avaliações sobre os resultados de politicas nela compreendida (como crédito rural, cédula da terra etc.), criaram um espaço no mercado de trabalho para os sociólogos rurais, mas, como afirmamos acima, restrito à execução de diretrizes de desenvolvimento estranhas ao próprio corpo teórico da disciplina. Penso que fornecemos mais instrumentos técnicos, metodologias de pesquisas etc., do que propriamente o conhecimento crítico da Sociologia Rural. Por fim, com o desmantelamento do Estado nas duas últimas décadas, vimos recuar substancialmente a possibilidade prática do exercício profissional para os sociólogos rurais, tanto o Incra quanto as secretarias de agricultura esvaziaram as possiblidades de pesquisa (mesmo restrita que existia anteriormente), e a Sociologia Rural sobrevive, sobretudo, em projetos no interior das próprias Universidades.

[Revista Prelúdios] "Entre 1985 e 2018, 1938 pessoas foram executadas 
em conflitos por terra, água e trabalho no Brasil e 1789 desses casos (92\%) continuam sem qualquer responsável julgado ou preso. [...] Do total de mortes, apenas 370 tiveram suspeitos identificados, mas apenas 117 julgamentos foram realizados. As condenações foram realizadas apenas para pouco mais da metade dos mandantes apontados pela polícia e um terço dos executores identificados". Os dados são da Comissão Pastoral da Terra - CPT (DIAZ, 2019, 12 jun. 2019). Na mesma reportagem, a procuradora dos direitos humanos do Ministério Público, Débora Duprat, alerta que "As propostas de Bolsonaro que visam armar os proprietários rurais vão deixar os lugares onde a violência já impera ainda mais violentos" (DIAZ, 2019, 12 jun. 2019). O conflito do campo resultado em morte é problema social que parece crônico no Brasil. Qual o balanço que o senhor faz desta problemática da questão agrária e qual o horizonte dela no atual governo do presidente eleito em 2018 ?

[Antônio Câmara] Creio que o balanço da questão agrária deve ir além do governo atual, pois quando localizamos o Plano de Reforma Agrária ainda no período Sarney, logo após o fim da ditadura militar, havia a expectativa de uma reforma agrária que poderia ser realizada em um espaço de quinze a vinte anos; o surgimento do MST como um movimento que exigia a expropriação de terras improdutivas e, particularmente, a sua tática ousada de ocupação de terras, parecia abrir um caminho alvissareiro para a reforma agrária. No entanto, os sucessivos governos atenderam de forma localizada e apenas como política paliativa a expropriação de terras. À força de suas ocupações o MST conseguiu impor uma política de assentamento que pouco a pouco perdeu força, atingindo o seu nível mais baixo no período de Dilma Rousseffe Michel Temer. A criminalização dos movimentos sociais já estava presente neste último período, mas a retórica ainda era favorável à reforma agrária. Já, no atual governo, a reforma agrária foi abolida completamente como politica, agravando-se com o armamento dos grandes proprietários e a decisão de não realizar mais nenhum assentamento rural. Até o último governo, o MST ainda tinha a ilusão de ser um interlocutor dos sem-terra, passivel de ser escutado pelos órgãos públicos, hoje aparece como um grupo fora da lei e suas ações são reprimidas pela força fisica. De certa forma, os governos petistas desarmaram politicamente o MST, o atraíram para uma falsa negociação com o Estado e conseguiram apoio politico para medidas mitigadoras. O MST, de certa forma, viu a sua independência enquanto movimento esvaziada e isso dificulta a necessidade atual de reagir a um governo protofascista. A longa relação amistosa como Estado desarmou o movimento. Enfim, foco mais na luta social, no seu apaziguamento no período petista $e$, consequentemente, na sua fragilidade atual do que na caracterização do governo autoritário e neofascista, pois o que importa é como os movimentos sociais podem recuperar o protagonismo nesse novo período. 
[Revista Prelúdios] Conte-nos, brevemente, o histórico de pouco mais de trinta anos do Núcleo de Estudos Rurais e Ambientais - Nuclear, do qual o senhor já foi coordenador algumas vezes e continua ligado como pesquisador.

[Antônio Câmara] O Nuclear, quando foi criado, contou com a participação de diversos professores do departamento de Sociologia com vasta experiência em pesquisa no estado da Bahia, na área de Sociologia Rural. Alguns desses colegas já se encontram aposentados como Sérgio Elísio Peixoto, Solon Santana Fontes e Altino Bomfim, e o saudoso professor João Saturnino. Do departamento de Antropologia, contamos com a participação da professora aposentada e ex-diretora da Faculdade de Filosofia e Ciências Humanas (FFCH) Sylvia Maia, responsável pela primeira reforma do espaço no qual funcionamos. Além disso, tivemos a participação de Guiomar Germani, do departamento de geografia humana (Instituto de Geociências) e de Francisco Emanuel Brito, técnico da Companhia de Desenvolvimento e Ação Regional da Bahia - CAR-BA. Mais tarde, juntou-se ao nosso Núcleo a professora Lídia Cardeal, que o integra até os dias atuais. Mais recentemente novos colegas passaram a compor o grupo como a professora Maria Salete (Ciência Politica) e Luiz Henrique (Sociologia) e pesquisadores que no passado foram orientandos meus ou de Lídia. A primeira e ambiciosa proposta que nos unificou na época da criação do Nuclear foi a pretensão de realizar uma ampla pesquisa sobre a estrutura agrária e a reforma agrária na Bahia. Por falta de financiamento, não se concretizou o que seria uma agenda de pesquisas, no entanto, ao longo dos anos, certamente esse propósito foi levado a cabo, tanto através de nossos projetos envolvendo a questão rural, os movimentos sociais, relação entre mídia e movimentos sociais, ideologia, cinema documentário etc, (no âmbito do PIBIC e do Programa Permanecer), quanto através da orientação de monografias, dissertaçôes e teses sobre a questão rural, sob minha responsabilidade ou de Lídia Cardel no âmbito do departamento de Sociologia ou na Pós-Graduação em Ciências Sociais na UFBA. Algumas pesquisas mais amplas ocorreram ao longo desse tempo, como a participação em Censo da Reforma Agrária e pesquisa sobre crédito rural, ambas em conjunto com outras Universidades do país; registro também atividades de extensão dos professores Altino Bomfim e Lídia Cardel. Por fim, creio que a pesquisa mais importante que realizamos, "Estudos socioambientais e saberes tradicionais do litoral norte da Bahia: diálogos interdisciplinares", no âmbito do convênio Capes-Cofecub (instituição de fomento à pesquisa na França), envolvendo a UFBA e a Universidade de Estrasburgo entre 2010 e 2103. Todas estas atividades fortaleceram o Nuclear e até mesmo abriram caminho para outras pesquisas em áreas distintas da Sociologia, permitindo hoje que tenhamos áreas de pesquisa distintas daquela original.

[Revista Prelúdios] Entre 2010 e 2013, o senhor coordenou a pesquisa "Interações bioculturais e desenvolvimento rural sustentável em região de Mata Atlântica: saberes e práticas naturais, mobilidades e dinâmicas territoriais", 
fruto de um convênio entre a CAPES e a instituição de fomento à pesquisa na França (COFECUB), que foi desenvolvida no Litoral Norte baiano. Como o senhor avalia o encontro entre a indústria do turismo e as comunidades pesqueiras de ética camponesa nessa região?

[Antônio Câmara] Esta pesquisa envolveu um número significativo de professores de várias áreas da UFBA (Biologia, Educação e Ciências Sociais) e da Universidade de Estrasburgo (Antropologia, Sociologia e Etnobiologia), estudantes de mestrado e doutorado e um pesquisador em estágio de pós-doutorado. Conseguimos, tanto através da pesquisa original quanto pela contribuição das demais pesquisas, traçar um amplo painel de transformações ocorridas no litoral norte. Foi possível observar que as localidades que estudamos sofreram fortes impactos do turismo e da expansão da plantação de eucaliptos. Especificamente quanto ao turismo foi possivel verificar a destruição da produção agrícola local, a forte atração que os resorts exercem sobre a população nativa que tem muitos dos seus membros empregados nestes centros turísticos e, sobretudo, a forte adaptação da produção artesanal local ao turismo, incluindo os modelos de produção importados (forma, coloração etc.). Percebemos alteração também na produção pesqueira, as localidades costeiras abandonaram tanto a pesca quanto a agricultura, adaptando seus negócios ao turismo. Os estudos sociológicos sobre o turismo já haviam chamado a atenção para o forte impacto desta atividade sobre comunidades locais, pois a maior parte da força de trabalho volta-se para atender o interesse crescente dos turistas pela região. Por outro lado, a chamada "indústria turística" de massas é voraz e volátil, expande-se constantemente para áreas novas, molda-as de acordo com o interesse de seus futuros clientes, cria espaços protegidos nos quais esses possam sentir-se em casa, com a mesma comodidade de suas vidas cotidianas; mas o principal problema do turismo em comunidades locais é o seu caráter predatório, pois torna a experiência dos seus clientes homogênea e, para isso, precisa também destruir a diversidade local, restrita a algumas atividades caricaturais - no caso do litoral norte é visível o uso do artesanato como única singularidade. Mas os estudos também mostram que isso é passageiro, pois em curto espaço de tempo o capital buscará novas regiões inexploradas, abandonando aquelas que perderamo encanto. Aparentemente, tentando minimizar os efeitos destruidores deste padrão de expansão, os governos locais fazem o discurso e promovem legislações e medidas que poderiam ir na direção da integração entre o turismo e as comunidades locais, através da ordenação da especulação imobiliária, da preservação dos recursos naturais e do modo de vida da população. Mas, na prática, tanto os discursos quanto a legislação apenas encobrem a verdadeira natureza do capitalismo na sua voraz expansão para áreas interioranas. No caso do litoral norte foi possivel verificar que o planejamento ambiental previa medidas de preservação da natureza e do modo de vida, mas na prática isso desapareceu na medida em que o turismo avançou sobre a região. Nas comunidades pesqueiras vimos o fim da pesca, nas interiorizadas o fim 
da pequena produção agrícola, em ambas preserva-se, mas de modo distinto (incorporando novas técnicas de produção), o artesanato de piaçava voltado para o mercado turístico. Para concluir, observamos que os grupos que tinham o controle dos resorts como fundos públicos de pensão encontravam dificuldades para gerir e manter o padrão internacional do turismo, sobretudo devido ao fluxo reduzido de turistas provenientes da Europa. A situação atual certamente é mais grave, não só pela atual pandemia, mas pela crise econômica e financeira na qual o país se encontra mergulhado desde 2013.

[Revista Prelúdios] Como o senhor avalia a afirmação de José de Souza Martins (2001, p. 34): "[...] Há mais sociologia rural de alto refinamento em obras de Gabriel Garcia Marquez, Manuel Scorza, John Steinbeck, José Saramago, Juan Rulfo ou Guimarães Rosa do que em muitas de nossas análises complexas e elaboradas". Como a Sociologia Rural encontra substrato de pesquisa na literatura e nas artes em geral?

[Antônio Câmara] Eu concordo de modo parcial com essa observação, pois nenhum desses autores de fato estiveram preocupados em produzir Sociologia Rural, talvez o mais próximo de um relato com esse caráter tenha sido Manuel Scorza. Por outro lado, sem dúvida, alguns destes autores, em particular os da literatura fantástica, conseguiram recriar o imaginário rural através de seus personagens e de circunstâncias sociais. Certamente, do ponto de vista da supra estrutura, para compreender processos psicossociais, a literatura aporta uma imensa contribuição para o conhecimento do mundo rural. Mas, a meu ver, não substitui a pesquisa sociológica e deve ser compreendida como se propõe a ser, arte, recriação e imaginação do mundo. A Sociologia Rural, através de seus estudos empíricos e teóricos, tem buscado resolver dilemas da expansão capitalista sobre o mundo rural, podendo utilizar-se da arte e da literatura, mas tendo a certeza de que não substituem o conhecimento científico da realidade e não têm compromisso prévio com a análise e a descrição das relações sociais.

[Revista Prelúdios] Como o rural é representado no cinema brasileiro e no da América Latina?

[Antônio Câmara] Mantenho-me no campo do cinema no Brasil, pois para referenciar a questão na América Latina seria necessário um conhecimento mais profundo da produção cinematográfica do subcontinente. Em artigo que escrevi há algum tempo e nas pesquisas que tenho orientado observo alguns momentos significativos desta representação. Um primeiro momento no qual o mundo urbano refere-se ao rural como distante, exótico e atrasado, a exemplo dos filmes sobre o cangaço nos anos quarenta e cinquenta do século passado; um segundo momento, de valorização da luta camponesa, no qual o sertão do Nordeste aparece como síntese da luta revolucionária, 
superando o passado messiânico pela luta politica (Glauber Rocha representa 0 auge deste movimento cultural) e, na contramão da visão politizada, a valorização do modo de vida caipira em Mazzaropi. E, por fim, as formas de representação mais contemporâneas que aproximam o mundo rural do mundo urbano e tentam captar as transformações mais recentes, a exemplo de Bye Brasil (1977), Central do Brasil (1998) e O Caminho das Nuvens (2003). Não por acaso, predomina o Nordeste rural, ainda distante para 0 imaginário urbano e industrializado do sudeste do país. As películas mais recentes tentam superar essa distância, pondo lado a lado o urbano e o rural no próprio Nordeste, as tecnologias mais recentes aliadas à vida mais simples (como é caso do filme Bacurau, lançado em 2019).

[Revista Prelúdios] Ainda pode-se pensar numa Sociologia Rural sobretudo insulada em si? É possível realizarmos uma Sociologia da Sociologia Rural?

[Antônio Câmara] palam, um novo mundo inteiramente virtualizado onde desapareceria as distinções espaciais. Creio que a crença perfeita neste novo mundo tem nos levado aos paradoxos do avanço da extrema-direita que percebeu em vários países nichos conservadores nas regiões interioranas que sonham com um passado glorioso, como ocorreu com os EUA e alguns países da antiga Europa do leste. Enfim, o rural, como concebíamos no passado, deixou de existir, no entanto o mundo não se tornou uma grande pólis, pois a desigualdade e a variedade das relações sociais de produção seguem existindo e a mentalidade rural tem sido recriada pelos próprios meios tecnológicos. Quanto a uma sociologia da Sociologia Rural, talvez não seja necessário, pois pode ser uma armadilha, tal qual a sociologia do conhecimento, um constante retornar às origens, fazer a sua própria crítica, não creio ser o caminho para a Sociologia. Talvez o caminho seja o de avançar numa perspectiva da economia politica, pensando o rural como parte de toda a ampla rede de relações sociais no capitalismo, abrindo-se para as contribuições de todas as disciplinas próximas (sociologia e antropologia ambiental, sociologia do trabalho, sociologia da cultura e da arte, geografia rural e ambiental, economia rural, história etc). Talvez se trate de uma transição para a criação de nova disciplina mais robusta, por enquanto a Sociologia Rural se mantém e deve buscar ampliar seus horizontes.

\section{REFERÊNCIAS}

DIAZ, C. J. Desde 1985, 92\% das mortes no campo por disputa de terra seguem sem solução. IG, São Paulo, 12 jun. 2019. Último Segundo. Disponível em: https:// ultimosegundo.ig.com.br/brasil/2019-06-12/desde-1985-92-das-mortes-no-campopor-disputa-de-terra-seguem-sem-solucao.html. Acesso em: 20 out. 2019.

HANNIGAN, J. Sociologia Ambiental. Petrópolis: Vozes, 2009. 
KUHN, T. As estruturas da revolução científica. São Paulo: Perspectiva, 1962.

HOLSTON, J. Legalizando o ilegal: propriedade e usurpação no Brasil. In: HOLSTON, J. Cidadania insurgente: disjunções da democracia e da modernidade no Brasil. São Paulo: Companhia das Letras, 2013. p. 265-345.

MARTINS, J. S. A imigração e a crise do Brasil agrário. São Paulo: Pioneira, 1973.

MARTINS, J. S. Capitalismo e tradicionalismo. São Paulo: Pioneira, 1975.

MARTINS, J. S. Os camponeses e a política no Brasil. 2. ed. Petrópolis: Vozes, 1981.

MARTINS, J. S. Fronteira: a degradação do outro nos confins do humano. São Paulo: Hucitec, 1997.

MARTINS, J. S. O futuro da sociologia rural e sua contribuição para a qualidade de vida rural. Estudos avançados, São Paulo, v. 15, n. 43, p. 31-36, 2001.

SEGATO, R. L. Las estructuras elementales de la violência: ensayos sobre gênero entre la antropologia, el psicoanálisis y los derechos humanos. Bernal: Universidad Nacional de Quilmes, 2003.

SILVA, M. A. M. Os errantes do fim do século. São Paulo: Unesp, 1999. 